\title{
The Possibility of Correlation of Hardening Power for Oils and Polymers of Quenching Mediums
}

\author{
Małgorzata Przyłęcka and Wojciech Gęstwa \\ Poznan University of Technology, Poznań, Poland \\ Correspondence should be addressed to Małgorzata Przyłęcka, malgorzata.przylecka@put.poznan.pl
}

Received 27 March 2009; Accepted 3 September 2009

Recommended by Douglas Chrisey

\begin{abstract}
There are many literature references comparing the use of aqueous polymer quenching solutions with petroleum oil quenchants for a wide range of steels of varying hardenability and the relating parameters of describing properties of the quenching mediums. There are relatively little similar relating correlations between parameters of describing properties of the different quenching mediums. The quenchants used included: conventional quenching oil, martempering oil, and 5\% and $25 \%$ aqueous polymer quenchant solutions (APQSs) of a polymer quenchant. These quenching media were selected to represent a broad range of quench severities as quantified by cooling curve analysis (ASTM D 6482) using a standard Inconel 600 probe and the Tensi Agitation Device. The test of correlation conducted between the Hardening Power parameters according to examples of oils and polymers. The enable work results in applying the Hardening Power independently from equation calculated for different quenching mediums and their work parameters.
\end{abstract}

Copyright ( 2009 M. Przyłęcka and W. Gẹstwa. This is an open access article distributed under the Creative Commons Attribution License, which permits unrestricted use, distribution, and reproduction in any medium, provided the original work is properly cited.

\section{Introduction}

Optimal quenchant selection is dependent on cooling intensity which is dependent on many factors including steel mass and hardenability, quenchant selection, bath temperature, agitation and in case of aqueous polymer solutions, polymer concentration $[1,2]$. Typically, increasing quench bath agitation increases cooling rates and increasing quench bath temperature decreases cooling rates. For polymer quenchants, increasing polymer concentration decreases cooling rates. Currently, the most common method of assessing the cooling properties of a quenching medium is to use cooling (time-temperature) curves [2,3]. Grum and coworkers have also correlated ultrasound phenomena [Grum, Ravnik 2006] and cooling curve (time-temperature) behavior obtained by different quenching media [4] and quenching conditions with steel transformation and residual stress for throughhardened steel alloys such as AISI 4140 [5], [Grum, et al. 2002]. However, in Segeberga works [7-9, 11] we can find the method of calculating Hardening Power parameter, the parameter describes cooling as centres abilities taking into account their conditions of work.
In this paper, the effect quenching medium selection and quench severity for different quenching mediums and alternative used the equation of Segeberg for oil and water polymer solution.

In work it was showed, that it is the possibility of delimitation between examples the correlation the describing the equation HP for oils and the water polymer solutions.

Odwołać się w wstẹpie do literatury Segeberga.

\section{Experimental}

The chemical compositions of steels used for this work are shown in Table 1.

Test specimens were machined from each steel material and these included $\varnothing 12 \times 6$. After machining, the test specimens were polished and then normalized at $890^{\circ} \mathrm{C}$ for 0.5 hour. The normalization process was conducted using protective atmosphere, with a dissociated ammonia. After cooling and drying, the protection atmosphere with a dissociated ammonia of type $\mathrm{H}_{2}-\mathrm{N}_{2}$ had the temperature of dew point about $-60^{\circ} \mathrm{C}$. In this atmosphere the quantity of no dissociated ammonia does not cross $0.005 \%$. The 
TABLE 1: Chemical composition of 1045 steel.

\begin{tabular}{lcccccccccc}
\hline Steel alloy & $\begin{array}{c}\text { The } \\
\text { classification } \\
\text { norm }\end{array}$ & C & Mn & Si & Cr & Ni & Cu & P max & S max & Inne \\
\hline 1045 & PN-92/H-84009 & $0.42-0.50$ & $0.50-0.58$ & $0.17-0.37$ & Max 0.30 & Max 0.30 & Max 0.30 & Max 0.040 & Max 0.040 & Mo Max 0.10 \\
\hline
\end{tabular}

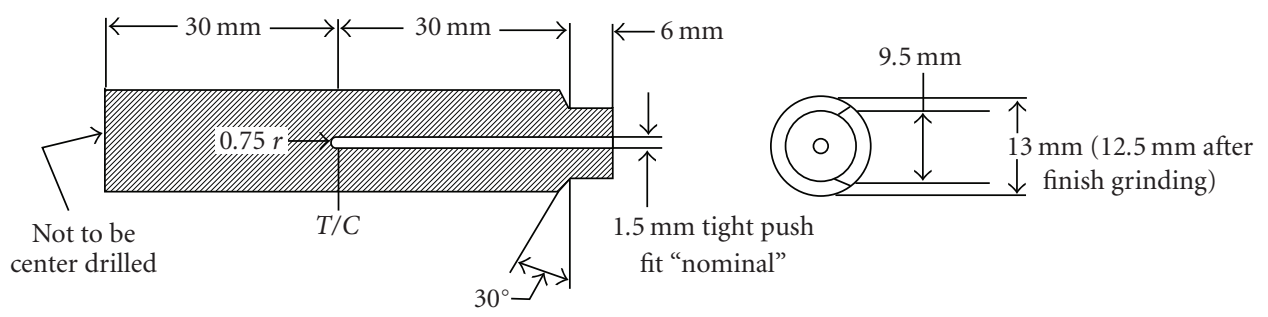

(a)



(b)

FIGURE 1: Schematic illustration of the so-called Wolfson probe used in ASTM D6482: (a) probe details, (b) general assembly.

grain size after normalization was ASTM 7 and was determined according to ASTM E112 "Standard Test Methods for Determining Average Grain Size." The test specimens were austenitized at $860^{\circ} \mathrm{C}$ for 0.5 hour in a dissociated ammonia protective atmosphere and quenched in one of the quenchants shown in Table 2. The quenchants used for this study included: $\mathrm{OH} 70$ which is a conventional petroleum oil-based quenchant manufactured by Petrol Oil in Płock, Poland; Mar-Temp -340 (v.890) which is an accelerated hot-oil manufactured by Houghton-Poland Sp. z o.o.; Breox Quenchant A which is an aqueous polymer quenchant concentrate manufactured by Cognis Corporation and was diluted to the desired concentration using distilled water prior to use.

To assess quench severity, cooling curve analysis were performed using an Inconel 600 cylindrical probe ( $\varnothing 12.5 \mathrm{~mm}$ dia $\times 60 \mathrm{~mm}$ long) and a Tensi agitation device which is according to described ASTM D6482-06 Standard Test Method for Determination of Cooling Characteristics of Aqueous Polymer Quenchants by Cooling Curve Analysis with Agitation (Tensi Method) is shown in Figures 1 and 2 , respectively. The experimental time-temperature data was smoothed using Fourier computational methodology reported earlier by [6].
The different quenchants and agitation rates used for this work are summarized in Table 2.

Hardness was measured using Rockwell hardness tests according to ASTM E18-00-Standard Test Methods for Rockwell Hardness and Rockwell Superficial Hardness of Metallic Materials and Vickers hardness tests according to ASTM E92-82-Standard Test Method for Vickers Hardness of Metallic Materials using a load of 0.981 [N] $(0.1[\mathrm{kG}])$ on a Zwick hardness tester.

Microstructure was determined using Philips XL-30 scanning microscope by $2000 \mathrm{X}$ magnification. Metallographic test specimens were etched with nital. Grain size was quantified according to ASTM E112 "Standard Test Methods for Determining Average Grain Size.”

\section{Experimental Resualts and Analysis}

3.1. The Cooling Curve of Quenching Mediums. The first step in the assessment is to determine the cooling curve for used quenching mediums.

The cooling curves for the different quenching media and conditions are shown in Figure 3. The curves are shown separately to facilitate their visual comparison although it is difficult to obtain useful comparative data by visual 
TABLE 2: Quenching media used in hardening of steel.

\begin{tabular}{lcc}
\hline Quenchant & Quench bath temperature $\left[{ }^{\circ} \mathrm{C}\right] ;\left(T_{b}\right)$ & Agitation rate $[\mathrm{m} / \mathrm{s}]\left(V_{b}\right)$ \\
\hline $5 \%$ water polymer solution (Breox quenchant A) & 30 & 0.24 \\
$5 \%$ water polymer solution (Breox quenchant A) & 30 & 0.52 \\
25\% water polymer solution (Breox quenchant A) & 30 & 0.24 \\
$25 \%$ water polymer solution (Breox quenchant A) & 30 & 0.52 \\
OH70 oil & 60 & 0.51 \\
Mar-temp 890 oil & 100 & 0.52 \\
\hline
\end{tabular}

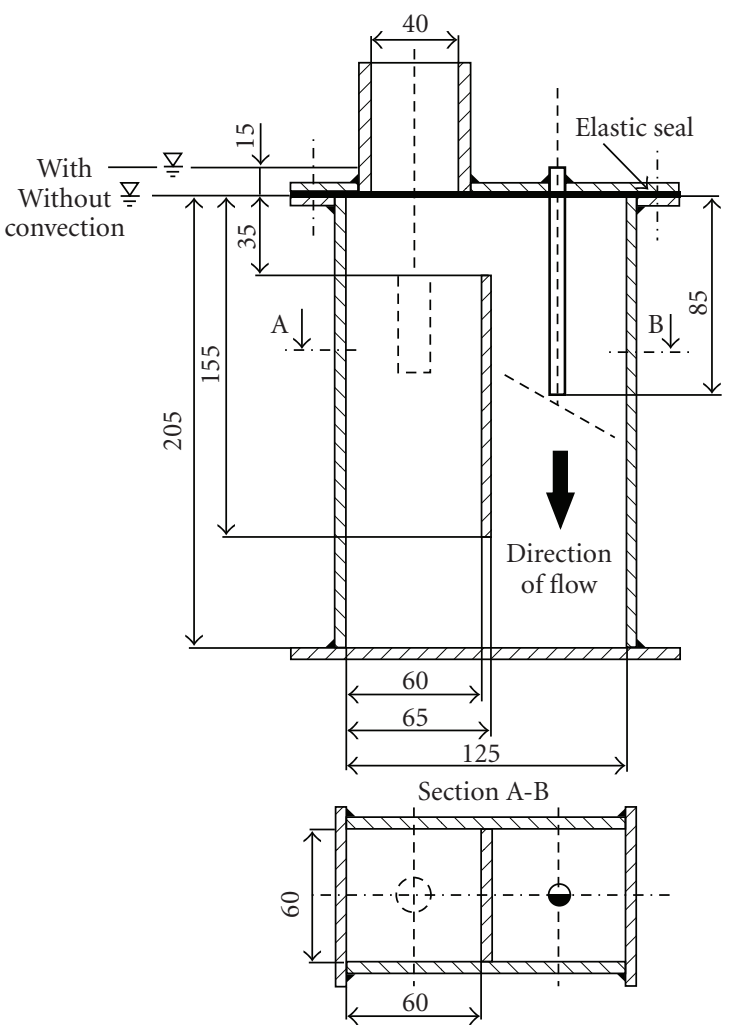

FIgURE 2: Schematic illustration of the tensi impeller-driven agitation device used in ASTM D6482.

inspection. Therefore, a numerical analysis of the cooling time-temperature and cooling rate curves is performed and the data obtained is summarized in Table 3 .

These data show that the cooling rates at both $550^{\circ} \mathrm{C}$ and $330^{\circ} \mathrm{C}$ were the greatest for the $5 \%$ aqueous polymer quenchant solution (APQS). At $550^{\circ} \mathrm{C}$ the cooling rate was essentially independent of agitation rate for the 5\% $\mathrm{APQS}$ but at $330^{\circ} \mathrm{C}$ the cooling rate was slightly greater for the higher agitation rate $(0.24$ versus $0.53 \mathrm{~m} / \mathrm{s})$. When the polymer quenchant concentration was increased from $5 \%$ to $25 \%$, the cooling rates for the $25 \% \mathrm{APQS}$ at both $550^{\circ} \mathrm{C}$ and $330^{\circ} \mathrm{C}$ were, as expected, less than those exhibited by the $5 \%$ APQS at either agitation rate. Also, as expected, the cooling rates of the $25 \%$ APQS increased with agitation rate. The conventional $\mathrm{OH} 70$ petroleum oil and the Mar-Temp 340 (v.890) oil both exhibited cooling rates similar to each other at both $550^{\circ} \mathrm{C}$ and $300^{\circ} \mathrm{C}$, which were intermediate between the cooling rates exhibited by the 25\% APQS at 0.24 and $0.53 \mathrm{~m} / \mathrm{s}$ agitation rates.

Further analysis of the quantitative cooling data in Table 3 involves the $T_{\mathrm{VP}}$ or Leidenfrost temperature where film-boiling to nucleate boiling transition occurs and $T_{\mathrm{CP}}$ is the temperature where the transition from nucleate boiling to convective cooling occurs. In addition, the time for nucleate boiling to begin was also determined. Interestingly, although distilled water at $30^{\circ} \mathrm{C}$ exhibited the fastest cooling rates, it also exhibited the lowest $T_{\mathrm{VP}}$ and $T_{\mathrm{CP}}$ temperatures of any of the quenchants evaluated. Additionally, all of the other quenchants exhibited $T_{\mathrm{VP}}$ and $T_{\mathrm{CP}}$ temperatures approximately equivalent to each other and all were greater than the values shown for water. These data illustrate the difficulty in trying to obtain a relatively simple analysis of the quench severity exhibited by different quenching media.

3.2. Development of the Segerberg Hardening Power (HP) Equations. Segerberg has developed a test using the $12.5 \mathrm{~mm}$ dia $\times 60 \mathrm{~mm}$ INCONEL 600 cylindrical probe (so-called Wolfson probe) to quantify the quench severity of an unagitated oil quenchant as described in ASTM D6200 [7$9,11]$.

This was done by determining the hardening power (HP) of 23 conventional and accelerated hot and cold quench oils, whose cooling properties varied from the fastest to the slowest that were commercially available [7]. Hardening power refers to the cooling capacity or ability of a quenchant to harden steel, not the relative cooling rate. Also, it was reported that there is no correlation between the Segerberg hardening power (HP-value) and the classic Grossman quench severity (H-value).

Segerberg used the quenching data obtained from the analysis of the quenchants develops a quantitative description of hardening power which was based on three transition temperatures obtained from the cooling rate curve shown in Figure 4 for each quenchant where [7]

(i) $T_{\mathrm{VP}}$ is the transition temperature in $\left({ }^{\circ} \mathrm{C}\right)$ between the film-boiling (vapor-cooling) stage and the nucleate boiling stage of the cooling process;

(ii) $\mathrm{CR}$ is the cooling rate $\left({ }^{\circ} \mathrm{C} / \mathrm{s}\right)$ over the temperature range of $500-600^{\circ} \mathrm{C}$;

(iii) $T_{\mathrm{CP}}$ is the transition temperature $\left({ }^{\circ} \mathrm{C}\right)$ between the nucleate boiling stage and the convective cooling stage of the cooling process. 


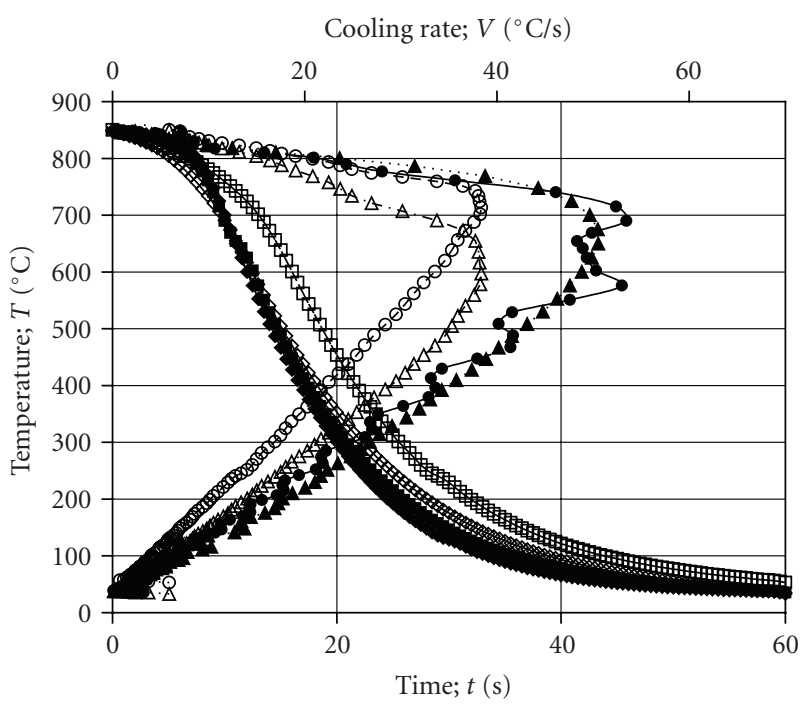

$\rightarrow T=f(t)-5 \%$ water polymer solution $\left(T_{b}=30^{\circ} \mathrm{C} ; V_{b}=0.24 \mathrm{~m} / \mathrm{s}\right)$

- $\quad T=f(t)-5 \%$ water polymer solution $\left(T=30^{\circ} \mathrm{C} ; V=0.53 \mathrm{~m} / \mathrm{s}\right)$

-曰- $T=f(t)-25 \%$ water polymer solution $\left(T_{b}=30^{\circ} \mathrm{C} ; V_{b}=0.24 \mathrm{~m} / \mathrm{s}\right)$

$\prec-T=f(t)-25 \%$ water polymer solution $\left(T_{b}=30^{\circ} \mathrm{C} ; V_{b}=0.52 \mathrm{~m} / \mathrm{s}\right)$

$\longrightarrow T=f(V)-5 \%$ water polymer solution $\left(T_{b}=30^{\circ} \mathrm{C} ; V_{b}=0.24 \mathrm{~m} / \mathrm{s}\right)$

.ム. $T=f(V)-5 \%$ water polymer solution $\left(T=30^{\circ} \mathrm{C} ; V=0.53 \mathrm{~m} / \mathrm{s}\right)$

$-\Theta-T=f(V)-25 \%$ water polymer solution $\left(T_{b}=30^{\circ} \mathrm{C} ; V_{b}=0.24 \mathrm{~m} / \mathrm{s}\right)$

$-\Delta-T=f(V)-25 \%$ water polymer solution $\left(T_{b}=30^{\circ} \mathrm{C} ; V_{b}=0.52 \mathrm{~m} / \mathrm{s}\right)$

(a)



(b)

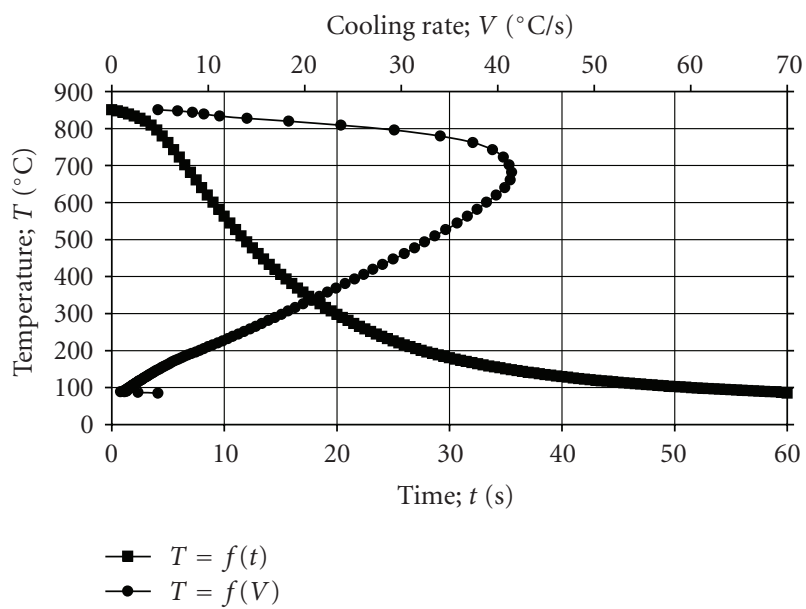

(c)

FIGURE 3: Cooling time and rate curves for (a) 5\%-25\% water polymer solution; (b) OH70 oil; (c) Mar-Temp 890 oil. (Quenching temperature and agitation rate were shown in Table 2 and the figure above.)

The $T_{\mathrm{VP}}, \mathrm{CR}$, and $T_{\mathrm{CP}}$ shown in Figure 4 represent three critical regions of cooling [7]. The length of the film-boiling phase is reflected in the value of $T_{\mathrm{VP}}$. The length of this phase must be sufficiently short so that the steel can be hardened and not so long so that the cooling process would extend into the ferrite-pearlite transformation region of the steel. The CR value must be sufficiently fast through the nose of the ferrite-pearlite transformation region, which is typically approximately $500-600^{\circ} \mathrm{C}$ for many steels, to minimize the potential formation of these transformation products. The value of $T_{\mathrm{CP}}$, the nucleate boiling to convective cooling transformation temperature, should be as low as possible to achieve maximum hardening potential. These cooling curve parameters were obtained for the quenchants shown in Figure 4. Least squares analyses was performed on the series of data for the different quenching oils and hardness data obtained using AISI 1045 steel test bars and a regression equation was developed [7-9]:

$$
\mathrm{HP}=91.5+1.34 T_{\mathrm{VP}}+10.88 \mathrm{CR}-3.85 T_{\mathrm{CP}} .
$$


TABLE 3: Summary of quenchants and quenching conditions.

\begin{tabular}{|c|c|c|c|c|c|c|}
\hline \multirow[t]{2}{*}{ Parameters } & \multicolumn{2}{|c|}{$\begin{array}{c}5 \% \text { aqueous } \\
\text { polymer solution }\end{array}$} & \multicolumn{2}{|c|}{$\begin{array}{c}25 \% \text { aqueous } \\
\text { polymer solution }\end{array}$} & \multirow{2}{*}{$\begin{array}{c}\text { Conventional quench } \\
\text { oil OH70 } \\
5\end{array}$} & \multirow{2}{*}{$\begin{array}{l}\text { High temper oil } \\
\text { Mar-Temp } 890 \\
6\end{array}$} \\
\hline & 1 & 2 & 3 & 4 & & \\
\hline $\begin{array}{l}\text { Quench bath } \\
\text { temperature }\left[{ }^{\circ} \mathrm{C}\right]\end{array}$ & 30 & 30 & 30 & 30 & 60 & 100 \\
\hline Agitation rate $[\mathrm{m} / \mathrm{s}]$ & 0.24 & 0.52 & 0.24 & 0.52 & 0.51 & 0.52 \\
\hline$V 550\left[{ }^{\circ} \mathrm{C} / \mathrm{s}\right]$ & 47.6 & 46.3 & 31.4 & 37.6 & 35.2 & 36.9 \\
\hline$V 330\left[{ }^{\circ} \mathrm{C} / \mathrm{s}\right]$ & 26.8 & 30.1 & 18.6 & 24.5 & 19.8 & 20.7 \\
\hline $\operatorname{Tvp}{ }^{1}\left[{ }^{\circ} \mathrm{C}\right]$ & 831 & 823 & 774 & 800 & 834 & 828 \\
\hline $\operatorname{Tcp}^{2}\left[{ }^{\circ} \mathrm{C}\right]$ & 89 & 78 & 179 & 109 & 132 & 159 \\
\hline $\begin{array}{l}\text { Time for nucleate } \\
\text { boiling to begin }[\mathrm{s}]\end{array}$ & 33 & 31 & 19.2 & 32.2 & 34.7 & 31 \\
\hline $\mathrm{HP} 1^{3}$ & 1380 & 1404 & 768 & 1153 & 1082 & 990 \\
\hline $\mathrm{HP} 2^{4}$ & 330 & 371 & 172 & 266 & 199 & 217 \\
\hline Core hardness $(\mathrm{HRC})^{5}$ & 35 & 37 & 21 & 21 & 21 & 25 \\
\hline Core hardness (HV0.1) & 367 & 370 & 310 & 299 & 317 & 365 \\
\hline
\end{tabular}

(1) $T_{\mathrm{VP}}$ is the transition temperature in $\left({ }^{\circ} \mathrm{C}\right)$ between the film-boiling (vapor-cooling) stage and the nucleate boiling stage of the cooling process.

(2) $T_{\mathrm{CP}}$ is the transition temperature $\left({ }^{\circ} \mathrm{C}\right)$ between the nucleate boiling stage and the convective cooling stage of the cooling process.

(3) Hardening power (HP) was calculated using the Bodin-Segerberg equation for unagitated oils: $\mathrm{HP}=91.5+1.34 \times T_{\mathrm{VP}}+10.88 \times V 500-3.85 \times T_{\mathrm{CP}}$.

(4) Hardening Power (HP) was calculated (2) developed for agitated polymerquenchants; HP =3,54 $\times V 550+12.30 \times V 330-168$.

(5) The core hardness values were determined on the 1045 steel test specimens quenched as shown in the table. These hardnesses were determined after quenching.

Observe that the relative HP scale shown on the $x$-axis in figure with work [2] varies from approximately 10-1000 [7]. However, there are no actual hardness units on the $y$-axis because hardnesses were determined on different diameter bars and same locations, depending on the quench oil. Experimentally, the range of quench severity exhibited by these oils was sufficiently great that two different bar sizes, 10 and $16 \mathrm{~mm}$, for hardness determination were required [7]. For the fastest quenching oils, surface hardnesses were the same and core hardness varied which required the use of larger diameter test bars and for slower quench oils, core hardnesses were nearly equivalent and the surface hardness varied requiring the use of the smaller diameter test bars. Therefore, to include a single hardening power scale based on hardness measurements for AISI 1045 carbon steel is a relative ranking based on cooling curve parameters obtained for a wide range of quench oils-not a real correlation between hardness and HP obtained under a single set of quenching conditions.

It is also important to realize that different steels possess different cooling requirements with respect to $T_{\mathrm{VP}}$, CR, and $T_{\mathrm{CP}}$ which is dependent on the location of their CCT (continuous cooling transformation) curve with respect to time and temperature and the cooling profile of the quenchant. Therefore, while AISI 1045 will require the regression constants of $91.5,1.34,10.88$, and -3.85 shown for the previous HP equation, optimal prediction of hardness for other alloys will often require different regression constants and the relative ranking of the quench oils may be different as well [10]. Aqueous polymer quenchants are typically evaluated under agitation conditions as described in ASTM D6482 and D6549 and their cooling curves may exhibit either a suppressed or nonexistent film-boiling phase. In addition, the transition between nucleate boiling and convective cooling may not be clearly delineated in the cooling curve [11]. For cooling curves that exhibit this behavior, Segerberg proposed an alternative equation $[8,9]$

$$
\mathrm{HP}=3.54 \mathrm{CR}_{F}+12.30 \mathrm{CR}_{M}-168
$$

where

$\mathrm{CR}_{F}$ - cooling rate at the ferrite-pearlite nose of the CCT curve for the steel $\left({ }^{\circ} \mathrm{C} / \mathrm{s}\right)$;

$\mathrm{CR}_{M}-$ cooling rate at the martensite start $\left(M_{S}\right)$ temperature $\left({ }^{\circ} \mathrm{C} / \mathrm{s}\right)$.

The values of 3.54, 12.30, and -168 are regression constants.

It is important to note that the first HP equation shown above was developed for unagitated quench oils only. Agitated quench oils were never included in the first study. The second HP equation shown above was developed for agitation APQS and agitated quench oils were never included in this study. Therefore, a comparison of different quenchants including petroleum oils and APQS in the same study has never been reported. Furthermore no correlations between the HP data obtained by either equation for the same quenchants, irregardless of the as-quenched hardness, have also never been demonstrated. However, there remains the need to compare the relative quench severity of any quenchant on one scale based on cooling curve data obtained by a standardized quenching probe. This is one of the objectives of the work reported here. In addition, neither HP equation has been reportedly used for analysis of hardness of quenched carburized steels. 


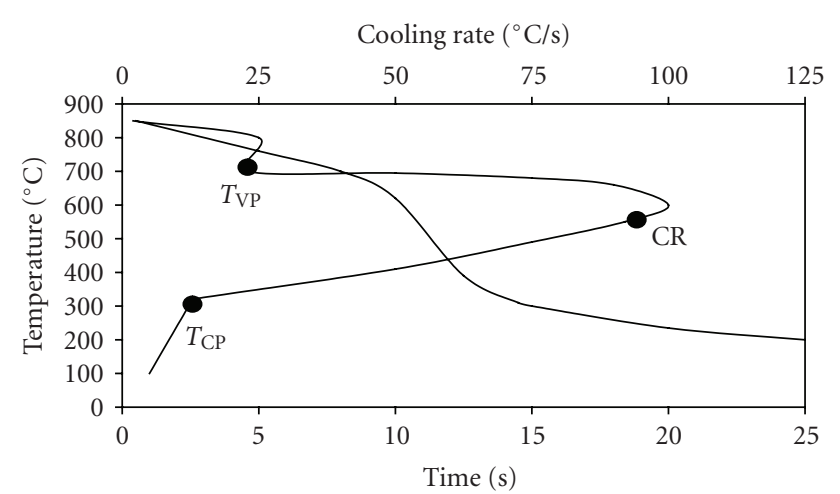

Figure 4: Cooling time-temperature and the cooling rate curve indicate transition temperatures for calculation of hardening power.

3.3. Application of Segerberg's HP Equations with Different Quenchants, Quenching Conditions. The equation developed under conditions of no agitation: $\mathrm{HP}=91.5+1.34 T_{\mathrm{VP}}+$ $10.88 \mathrm{CR}-3.85 T_{\mathrm{CP}}$ was designated as $\mathrm{HP} 1$. The equation developed for $\mathrm{APQS}$ with agitation: $\mathrm{HP}=3.54 \mathrm{CR}_{\mathrm{F}}+$ 12.30 CRM - 168 was designated as HP2. The hardening power of the quenching media and conditions shown in Table 3 was calculated by the two Segerberg equations. The order of hardening power determined by equation HP1 was water $>5 \%$ APQS $(0.24 \mathrm{~m} / \mathrm{s})>5 \%$ APQS $(0.52 \mathrm{~m} / \mathrm{s})>25 \%$ APQS $(0.24 \mathrm{~m} / \mathrm{s})>\mathrm{OH} 70>$ Mar-Temp $890>25 \%$ APQS $(0.52 \mathrm{~m} / \mathrm{s})$. The order of hardening power calculated by equation HP2 was nearly the same except that the HP2 was greater for Mar-Temp 890 than OH70: water $>5 \%$ APQS $(0.24 \mathrm{~m} / \mathrm{s})>5 \%$ APQS $(0.52 \mathrm{~m} / \mathrm{s})>25 \%$ APQS $(0.24 \mathrm{~m} / \mathrm{s})$ $>$ Mar-Temp $890>$ OH70 > 25\% APQS $(0.52 \mathrm{~m} / \mathrm{s})$. These data show that HP1 and HP2 produce hardening power values that generally follow the same trends. Figure 5 shows that a good correlation between HP1 and HP2 was obtained between for the data shown in Table 3. The linear regression equation obtained exhibited a correlation coefficient of R2 = 0.965 for the correlation equation

$$
\mathrm{HP} 2=0.3648 \times \mathrm{HP} 1-160.48 .
$$

Because of the figure in work [2] there is the perception that the equation HP1 can be used to predict hardness for any through-hardened steel alloy. However, it has been shown that the reliability of this equation was dependent on the hardenability of the steel alloy [10]. Neither equation HP1 or equation HP2 has been applied to the prediction of core hardness of steel. Another objective of this work was to examine the potential applicability of HP1 and HP2 to predict core hardness of steel.

Figure 6 shows the linear correlation results for superficial hardnesses obtained on quenched 1045 steel test specimens. The upper line was obtained for the HP1 versus HV0.1 core hardness correlation and the lower line was obtained for the HP2 versus HV0.1 core hardness correlation. Correlation coefficients, $R_{2}$ of 0.57 and 0.621 , respectively, were obtained which is rather poor. Somewhat better correlation coefficients $R_{2}$ of 0.82 and 0.901 were obtained for the HP1 and HP2 correlations with core hardness, respectively, as

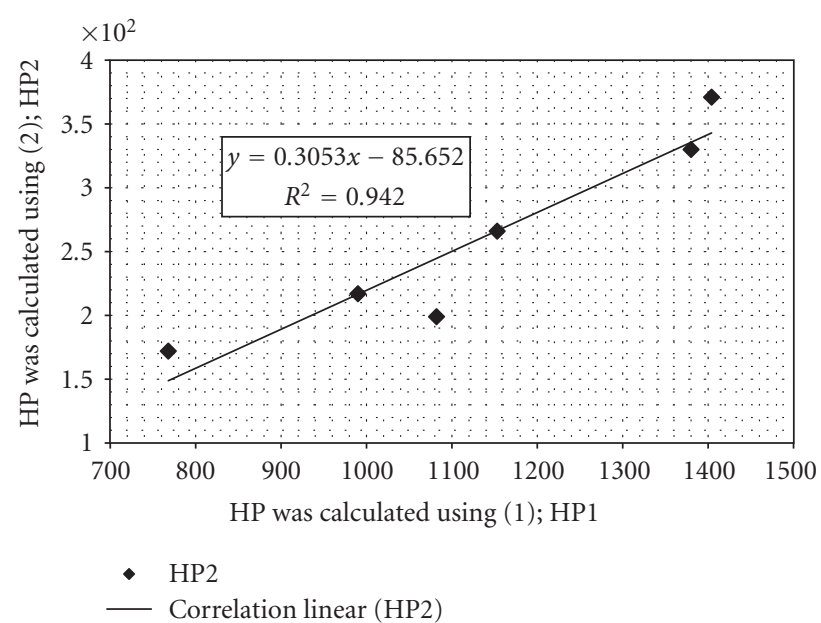

FIGURE 5: Correlation between the hardening power calculated by Segerberg's equation for oil quenchants no agitation (HP1) and Segerberg's equation for polymer quenchants with agitation (HP2).

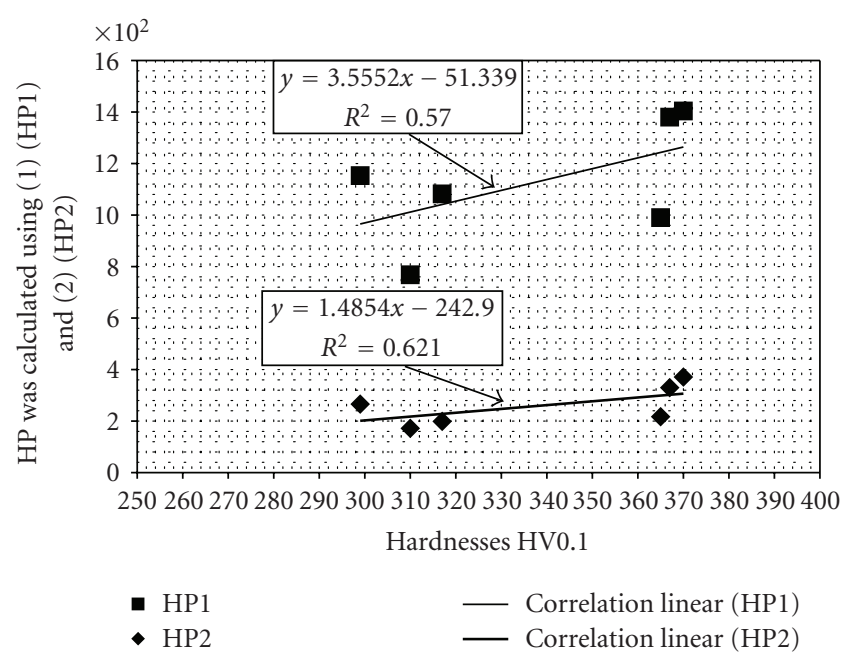

FIGURE 6: Linear correlation results for superficial hardnesses obtained on quenched 1045 steel. The upper line was obtained for the HP1 versus HV0.1 core hardness correlation and the lower line was obtained for the HP2 versus HV0.1 superficial hardness correlation.

shown in Figure 7, which although somewhat better than the superficial hardness correlations, both are still rather poor. The correlations for HP2 are marginally better than HP1 although when the overall correlation of the data is not good, the observed differences are probably not significant. Based on these data, the published equations for HP1 and HP2 are inadequate for quenched hardness predictions for 1045 steel. If an equation for such a correlation is desired, then it must be derived independently.

Figures 6 and 7 present the possibility of utilization of opinion of quenching mediums in support about Hardening Power parameter both according to (1) and (2). The HP parameter was presented in function of hardness, because this propriety of material was used for delimitation of 


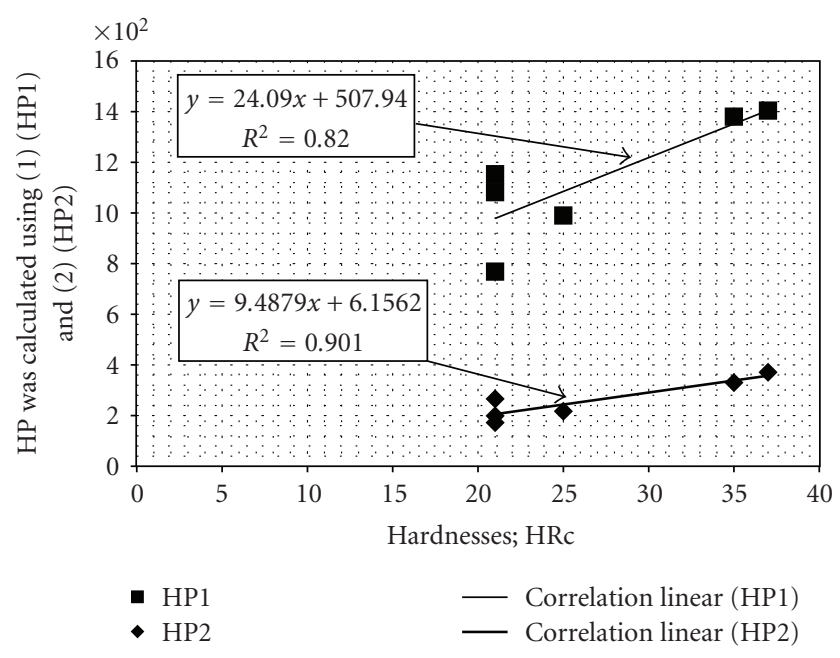

FIGURE 7: Linear correlation results for core hardnesses obtained on quenched 1045 steel. The upper line was obtained for the HP1 versus HRC correlation and the lower line was obtained for the HP2 versus HRC correlation.

examples 1 and 2, both for oils without circulation, as for polymers in agitation. Therefore it was allowed to present how the most this character figure. Obviously these equations were appointed for definite conditions, but how the own investigation showed these equations, we can use independently the quenching mediums kind being in agitation (oil or polymer water solutions). These figures show the correlations of HP1 and HP2 parameters with hardness of samples measured the method Rockwell and the Vickers on the same surfaces. The correlation showed that report between values HP1 and HP2 and similar course has with hardness formed way of measurement independently. This testifies about the possibility of exchangeable applying of equations to marke the value of parameter of the HP, and the same applying (1) both to oils and the polymer quenching mediums.

\section{Conclusions}

The quench severity of different quenchants was quantified using the Segerberg hardening power equations for unagitated quenchants (HP1) and agitated quenchants (HP2). Although a reasonably good correlation between HP1 and HP2 was shown, it was also shown that neither HP1 nor HP2 could successfully used in their published form to predict either core hardnesses of quenched 1045 steels. However, it is proposed that the HP values obtained by either HP1 or HP2 could be used to characterize the relative ability for a series of quenchants to harden steel.

\section{References}

[1] J. Grum and S. Božič, "Influence of steel masses and quenchants on mechanical properties of steel," International Journal of Materials and Product Technology, vol. 24, no. 1-4, pp. 224-240, 2005.
[2] G. E. Totten, C. E. Bates, and N. A. Clinton, "Cooling curve analysis," in Handbook of Quenchants and Quenching Technology, chapter 3, pp. 69-160, ASM International, Materials Park, Ohio, USA, 1993.

[3] B. Lišcic, H. M. Tensi, and W. Luty, Theory and Technology of Quenching, Springer, New York, NY, USA, 1992.

[4] J. Grum, S. Božič, and M. Zupančič, "Influence of various quenching agents on residual stresses in steel after heat treatment," Materials Science Forum, vol. 347-349, pp. 621$626,2000$.

[5] J. Grum, S. Božič, and M. Zupančič, "Influence of quenching process parameters on residual stresses in steel," Journal of Materials Processing Technology, vol. 114, no. 1, pp. 57-70, 2001.

[6] I. Felde, T. Reti, and X. L. Chen, "Efficient data encoding and filtering for quenching analysis," in Proceedings of the 3rd International Conference on Quenching and Control of Distortion, G. E. Totten, B. Liscic, and H. M. Tensi, Eds., pp. 208-215, ASM International, Prague, Czech Republic, March 1999.

[7] S. O. Segerberg, "Classification of quench oils: a method of comparison," Heat Treating, pp. 30-33, 1988.

[8] J. Bodin and S. Segerberg, "Measurement and evaluation of the quenching power of quenching media for hardening," in Quenching and Carburising: Procedings of the Third International Seminar of the International Federation for Heat Treatment and Surface Engineering, pp. 33-54, The Institute of Materials, Melbourne, Australia, 1993.

[9] J. Bodin and S. Segerberg, "Measurement and evaluation of the power of quenching media for hardening," Heat Treatment of Metals, vol. 20, no. 1, pp. 15-23, 1993.

[10] C. Chen and J. Zhou, "Discussions on Segerberg formula concerning the hardening power of quenchants," Journal of Xi'an Jiaotong University, vol. 36, no. 1, pp. 78-82, 2002.

[11] J. Bodin and S. Segerberg, "Measurement and evaluation of the power of quenching media for hardening," in Proceedings of the 1st International Conference on Quenching and Control of Distortion, G. E. Totten, Ed., pp. 1-12, ASM International, Materials Park, Ohio, USA, September 1992. 

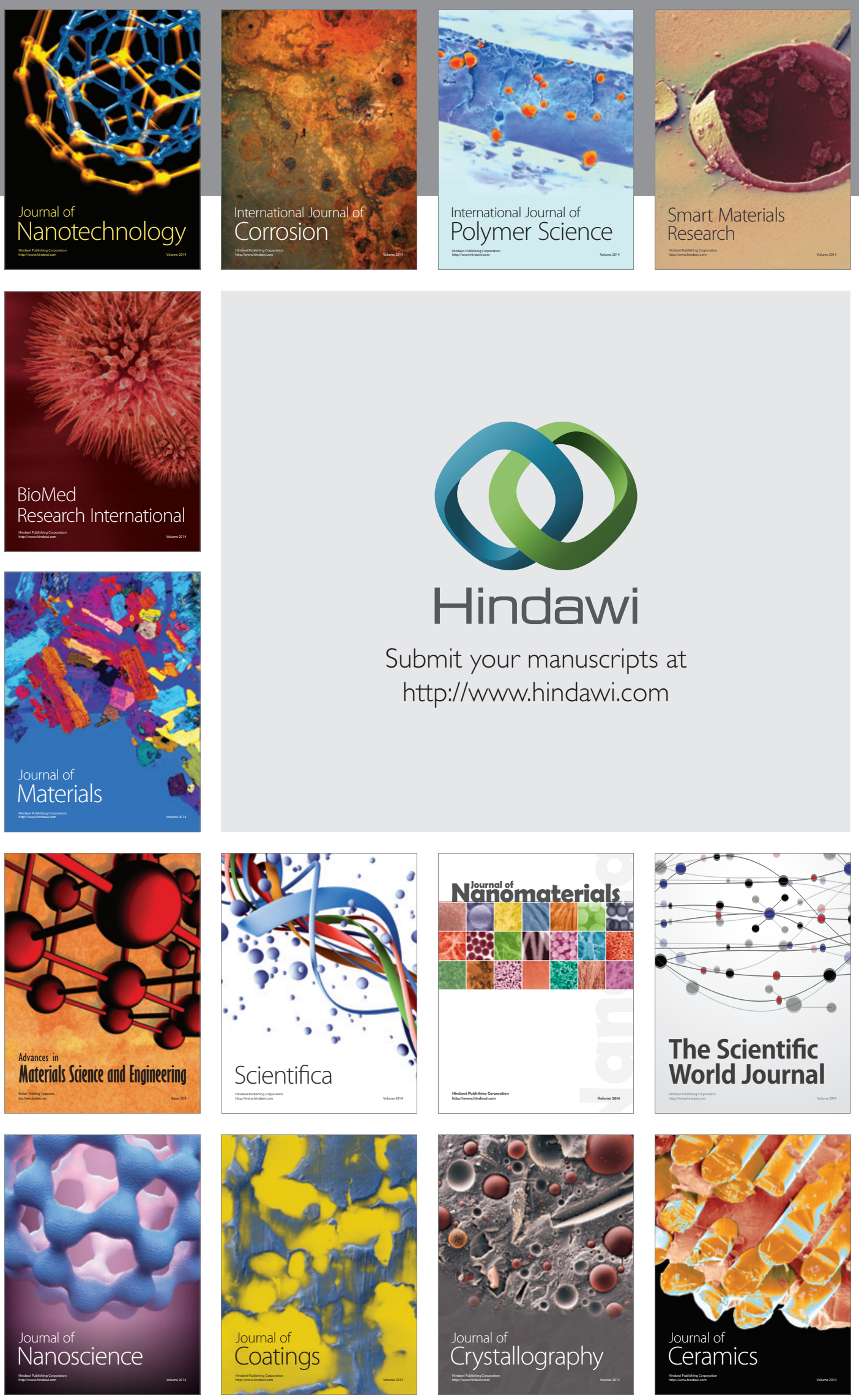

The Scientific World Journal

Submit your manuscripts at

http://www.hindawi.com

\section{World Journal}

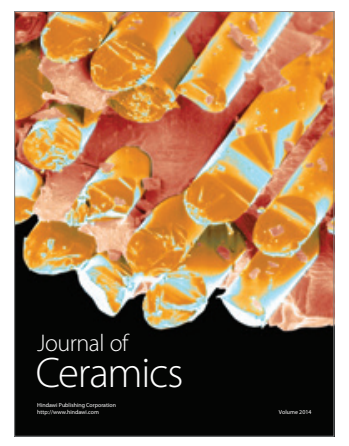

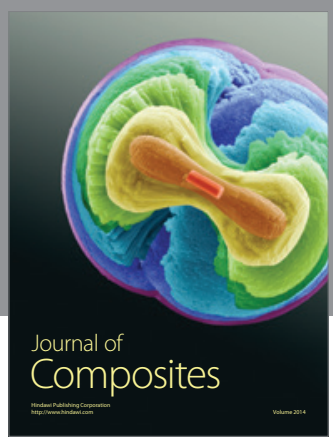
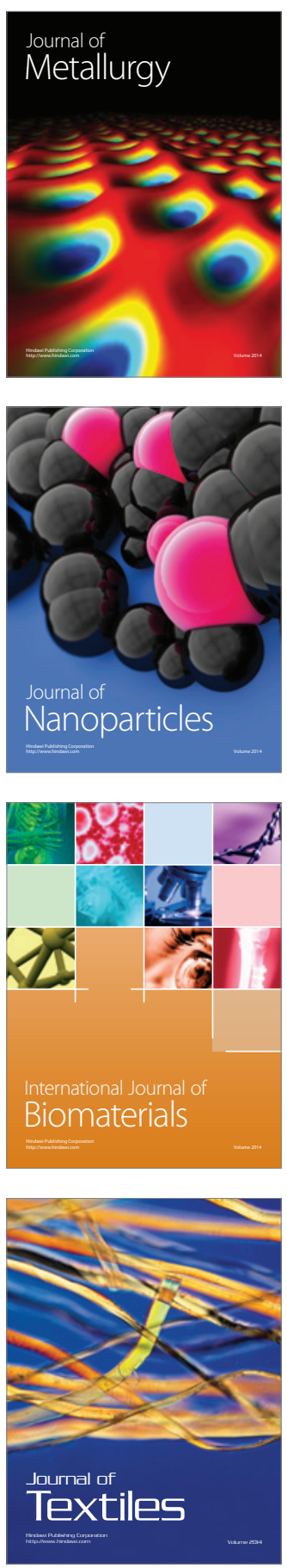